\title{
Methodological considerations in performing semantic- and translation-priming experiments across languages
}

\author{
Jeanette Altarriba and Dana M. Basnight-Brown \\ University at Albany, SUNY, Albany, New York
}

\begin{abstract}
Research in the field of bilingualism has had as its principal aim to describe the structure and function of memory for bilingual speakers. A primary technique that has been used to examine bilingual memory is an examination of cross-language word priming (semantic and translation), using the lexical decision and pronunciation tasks. Although studies have, on occasion, revealed greater degrees of word priming from a dominant to a subordinate language, in comparison with the reverse, a careful review of the methodology that has been used reveals a number of issues that render conclusions such as this quite problematic. Parameters of concern include language proficiency, cognate status, masking, control conditions, word frequency and length, stimulus onset asynchrony, relatedness proportion, and nonword ratio. These factors are discussed, as well as recommendations for conducting future empirical research in this area of investigation.
\end{abstract}

Bilingualism is much more common in the world than monolingualism, or the working knowledge of a single language (Bhatia \& Ritchie, 2004; Edwards, 2004; TabouretKeller, 2004). The idea that individuals can at once speak or process information in a single language domain yet switch to a second mode of thought based in an alternate language has fascinated researchers in such fields as psychology, linguistics, sociology, anthropology, neuroscience, and the like. In fact, little is known about exactly how the mind develops the capability to accurately store and process multiple languages in memory and to effectively operate as a monolingual in one of those languages. In addition, the terminology used to describe bilinguals has been confusing at times, since the term bilingual has the ability to include many different people, depending on the definition that is used. Although the scope of the following article is not to debate and define bilingual terminology, it must be stated that the term bilingual is used here to describe those who show "both regular use and communicative competence" in their two languages (Francis, 1999, p. 194).

Well over 40 years of research have been devoted to the area of bilingual memory and bilingual language processing in the cognitive domain. Most of this research has focused on questions of the nature of the bilingual lexicons and whether or not features such as those that represent conceptual relations or those that are lexically based are shared or are stored separately for a bilingual's two languages (see, e.g., Kolers, 1978, 1979; McCormack, 1976, 1977). These explorations have led to the development of various models of word representation for bilingual speak- ers that have specified the routes by which they retrieve various linguistic aspects of words from memory. In more recent theoretical perspectives, it has been argued that both a separate and a shared view of representation are correct but that they reflect processing for different types of bilinguals (i.e., early vs. late; see, e.g., Kroll \& Stewart, 1994). In newer formulations, processing issues have been examined apart from structural ones, and the focus has been more on connectionist theories and distributed models of representation in which the emphasis is more exclusively on the degree of featural overlap between words in different languages (see, e.g., Dufour \& Kroll, 1995). The latter models have been based on findings that indicate differential processing of different word types across languages and individual differences in memory representation for linguistic knowledge (see, e.g., Altarriba, 2003).

One of the main tools that researchers in this area have used to uncover the mental representation of more than one language in memory is the semantic-priming technique. This technique is hailed as one that provides the clearest evidence regarding the automatic processing of language, as compared with other techniques that engender the use of strategic processing (more will be said about this issue later in this review of methodology). In fact, this paradigm has become one of the most important tools used to determine whether or not a bilingual's languages are somehow interconnected and the levels at which this interconnectivity occurs.

The purpose of the present article is to examine the methodology and claims made in the published research investigating cross-language semantic priming and to

J.Altarriba,ja087@albany.edu 
outline various recommendations in methodology that researchers might follow when planning studies that involve this technique. Various other paradigms of related interest, such as negative priming (Fox, 1996), studies involving pictures as stimuli (Chen \& Ng, 1989, Experiment 2), studies in which cognate status has been manipulated (Cristoffanini, Kirsner, \& Milech, 1986), and those in which semantic categorization has been examined (Sánchez-Casas, Davis, \& García-Albea, 1992) will not be discussed, since the present review will have as its primary focus the literature that bears on the question of whether or not positive semantic priming occurs for cross-language words. The present review will focus only on work examining the use of the lexical decision task and the pronunciation task - the two major types of tools employed in this area of research. The literature is sizable; however, the present comprehensive review is timely in the development of this area of investigation and in the analysis of this body of work. The present review of methodology is an attempt to examine cross-language priming in a more focused and in-depth manner, where factors such as language proficiency, word frequency, word length, type of control, cognate use, relatedness proportion (RP), nonword ratio (NWR), stimulus onset asynchrony (SOA) length, and magnitude of priming effects are all examined and compared across experiments.

The present article will begin with a brief discussion of semantic priming in monolinguals. However, the bulk of the article will focus on the semantic-priming paradigm and how it has been used in the bilingual domain. This quantitative and qualitative discussion ends with a summary of some of the problems, or "pitfalls," in the methodologies used in many of the semantic and translation cross-language priming studies and with recommendations for future research.

\section{Semantic Memory and Priming in Monolinguals}

The organization of words and concepts in monolingual memory has been previously explored mainly by examining priming effects in lexical decisions (Meyer \& Schvaneveldt, 1971; Meyer, Schvaneveldt, \& Ruddy, 1975; Neely, 1977). This type of experimental paradigm, often used in cognitive psychology research, involves presenting participants with one or two letter strings on a computer screen. The participants are then instructed to decide as quickly and as accurately as possible whether or not the letter string composes a real word. This is often done by pressing one key if the letter string is a real word and a second key if a nonword is presented. The response times to each target item are then recorded for the participants. A priming paradigm involving a naming trial requires the participants to pronounce the target word aloud so that the response time can also be recorded and examined.

The concept behind semantic priming is that as a word is presented, automatic access to its meaning results in activation of both that concept and other concepts that are related to it. One of the most common effects that has been found to occur in lexical decision tasks is the semantic-priming effect. This effect occurs when prime and target words are semantically related, thereby producing faster response times than they would if they were unrelated. For example, the word $d o g$ semantically primes the word cat better than it does the word box, per se. In monolingual studies, semantic priming has proven to be a robust effect, found under several different experimental manipulations (for reviews, see McNamara \& Holbrook, 2003; Neely, 1991).

The spreading activation theory (Collins \& Loftus, 1975; Collins \& Quillian, 1969), which proposes that concepts are represented as nodes in a semantic network, is useful in predicting semantic-priming effects. According to this model, nodes representing respective concepts are connected via associative pathways, which suggests that semantically related concepts form stronger links or may be stored closer together than those concepts that are unrelated (Neely, 1991). When one node is activated, activation spreads along the network to other concept nodes that are located nearby. With regards to the semantic-priming effect, the activation of a semantically presented prime word leads to shorter response times to the target word, since the distance traveled is much less than it will be if an unrelated prime word is presented.

As was mentioned earlier, spreading activation theory rests on the assumption that words are automatically activated. This implies that the process must be fast acting and capacity free, occurs without intention, is involuntary, and can occur without conscious awareness (see Neely \& Kahan, 2001, for a more in-depth discussion on certain aspects of automaticity). However, it must be pointed out that even though automatic spreading activation is useful in explaining how words are represented internally, two other mechanisms have been proposed (Neely, 1991; Neely, Keefe, \& Ross, 1989). The three-process theory of semantic priming is important in that it introduces the possibility that participants employ strategies when responding to target words. The first additional mechanism suggests that participants use an expectancy strategy in which a list of words related to the prime is mentally constructed prior to the presentation of the target. Therefore, if the target word presented is semantically related, it may already be in the expectancy set, which will cause the response to be faster than it would have been under normal circumstances. Two of the main methodological issues thought to be responsible for utilization of this strategy are SOA and RP.

Relatedness proportion. The RP refers to the proportion of related prime-target trials out of all the primeword-target trials. It has been found that semantic priming increases in magnitude as the RP increases (de Groot, 1984). It has been suggested that as RP increases, participants will be more inclined to create expectancy sets because doing so will improve their performance, since most of the word pairs are related. However, if the RP is kept low, utilizing this strategy may prove to be less beneficial and may actually hinder one's performance (see Neely, 1991, for a more exhaustive review). Therefore, in order to obtain a fair estimate of priming effects, one will want to keep this proportion as low as possible when designing an experiment.

Stimulus onset asynchrony. A second factor that is capable of influencing whether an expectancy strategy is 
employed by participants is SOA length. This is described as the time interval between the presentation of the prime and the onset of the target or, more simply, how much time one has to think about the prime before the target appears on the screen. A long SOA can raise problems in that the extended time given makes it easier for participants to generate an expectancy set of related words. Initial research appeared to indicate that SOA lengths less than or equal to $300 \mathrm{msec}$ were capable of inhibiting any expectancy strategies. However, more recent work conducted by Hutchison, Neely, and Johnson (2001) has suggested that strategic priming still operates at a relatively short SOA of $300 \mathrm{msec}$. Their data indicated that when the SOA length was decreased to $167 \mathrm{msec}$, priming from a nonrepeated prime was no longer affected by RP. This implies that if semantic-priming facilitation is going to measure pure automatic priming effects in the absence of an operating expectancy mechanism, SOA length may need to be even shorter than was previously thought.

Nonword ratio. The second strategic process that may be utilized by participants in priming experiments is a semantic-matching strategy. This postlexical checking mechanism occurs after the target has been presented and participants check to see whether the prime and the target words are related, a process that may help them in making a final lexical decision. The RP and NWR of experimental word stimuli are most influential in determining whether or not this strategy is employed (Neely et al., 1989). The NWR is basically the proportion of nonwords out of all nonword and unrelated word pairs. When the NWR is below .5, participants may be biased to give a word response when a nonword has been presented. Meanwhile, if the NWR is above .5, a nonword response may be signaled, due to the large number of nonwords that have been encountered in the experiment. McNamara and Holbrook (2003) have pointed out that since equal numbers of word and nonword targets are usually used by researchers, the unrelated word pairs are usually fewer in number than the word-prime-nonword-target trials. This pattern in previous studies has led to NWRs that often exceed the recommended .5 value. However, it has also been suggested that semantic matching is due not to these factors and to the automatic spread of activation but, rather, to a composite cue that forms when the prime and the target combine at retrieval (Ratcliff \& McKoon, 1988).

Word length and word frequency. Additional methodological issues that do not deal primarily with strategic processes must also be taken into consideration when priming experiments of this nature are designed. Frequency (Balota \& Chumbley, 1984, 1985; Chumbley \& Balota, 1984; Monsell, Doyle, \& Haggard, 1989) and length of word primes and targets have been shown to affect the speed of word processing, recognition, and pronunciation. Balota and Chumbley (1990) have suggested that "the frequency with which one sees a word, retrieves a concept associated with a word, and retrieves information associated with a pronunciation of a word should have an influence on each of these components of word processing" (p. 236). Initial research conducted by Balota and Chumbley (1984) indicated that word frequency appeared to be more influential in lexical decision tasks, when compared with category verification and pronunciation tasks. Further work producing similar results led the authors to conclude that word frequency must influence a decision phase that occurs after lexical access (Chumbley \& Balota, 1984). In addition, Raveh (2002) has shown that prime frequency is an important factor in determining the size of priming effects. In this study, prime words that were characterized as having either high- or low-frequency inflection points revealed larger priming magnitudes for high-frequency inflections than for low.

In conclusion, research conducted over the past 30 years has consistently shown that the semantic-priming paradigm is an extremely useful experimental technique that allows cognitive psychologists to examine how words and concepts are represented in memory. However, as the present section has revealed, there are several methodological factors that must be controlled when an experiment is designed, especially if one wants to explore the automatic processes behind language representation. In the following section, studies in which the semanticpriming paradigm has been used to explore how two languages are organized in memory will be discussed. Unfortunately, several of these experiments appear to contain some flaws in their methodology, which may explain why there has been a large amount of variation in the results that have been reported. However, those cross-language priming studies in which an attempt was made to control certain factors are able to shed some light on the way in which two languages are organized in memory.

\section{Semantic Priming Across Languages}

In the past couple of decades, the semantic-priming paradigm has been expanded to include between-language stimuli, in order to gain insight into the way in which a bilingual's two languages are stored in memory. As was mentioned previously, there has been a long-standing debate over whether a bilingual person exhibits shared or separate language stores. If bilinguals do share a common conceptual store for their two languages, the automatic spreading activation model, as was discussed in the previous section, would predict that presentation of a prime word would activate semantically related words in a second language (L2). For example, a related word pair in this type of experiment could be composed of the prime word cat, followed by the target word perro, the Spanish translation of $d o g$. However, cross-language priming stimuli can be designed so that the prime is in the first (or dominant) language (L1) and the target is in the (weaker) L2 or vice versa. This allows researchers to examine different priming effects for each direction-L1-L2 and L2-L1.

Although this experimental technique has the potential to tap into the mental representation of both languages, the results from nearly one dozen priming studies have indicated a wide range of findings. Robust priming has been observed in both directions for some cross-language priming experiments (Chen \& Ng, 1989; Frenck \& Pynte, 1987; Keatley \& de Gelder, 1992, Experiment 1; Kirsner, Smith, Lockhart, King, \& Jain, 1984; Meyer \& Ruddy, 1974; Schwanenflugel \& Rey, 1986; Tzelgov \& Eben-Ezra, 
1992), whereas other research has yielded nonsignificant priming results (Frenck \& Pynte, 1987; Grainger \& Beauvillain, 1988; Keatley \& de Gelder, 1992, Experiments 2 and 3; Keatley, Spinks, \& de Gelder, 1994). In addition, confusion arises within this body of research, in that in a couple of studies, only priming in the L1-L2 direction has been examined (Larsen, Fritsch, \& Grava, 1994; Williams, 1994), which leads to an incomplete picture regarding representation and processing direction (see Appendix A for a study-by-study analysis of methodological issues in cross-language semantic priming experiments).

Language proficiency. As was seen in the previous section, there are many methodological issues that are capable of influencing priming effects. It is also possible that differences in the groups of participants used in many of these studies are to blame for the varied priming results. For example, some have suggested that more proficient bilinguals would exhibit greater priming effects than do those who are less proficient in their second language. However, results from a study conducted by Frenck and Pynte (1987) revealed nonsignificant priming effects for those whom they classified as "skilled bilinguals" and rather larger, significant priming effects for those determined to be "less-skilled" (see Appendix A). In addition, some have turned the importance away from proficiency and have suggested that age of acquisition is a stronger determinant of how much priming is observed. This brings up the question regarding the language history and proficiency of those who have participated in cross-language semantic-priming studies. Some participants have been described as learning both languages simultaneously or at a very young age (Grainger \& Beauvillain, 1988; Keatley \& de Gelder, 1992; Keatley et al., 1994; Larsen et al., 1994; Schwanenflugel \& Rey, 1986; Tzelgov \& Eben-Ezra, 1992), whereas others appear to have acquired their L2 around adolescence (Chen \& Ng, 1989; Kirsner et al., 1984, Experiment 5). Lastly, there were those participants who appeared to be proficient in both languages but who had acquired their L2 during or near adulthood (Frenck \& Pynte, 1987; Meyer \& Ruddy, 1974; Williams, 1994). In addition to differences in age of acquisition, it is also quite probable that differences in proficiency existed. Even though many of the participants were described as being fluent in both languages, the language questionnaires that were frequently used may have led some people to overestimate their proficiency level, whereas others felt that their skills were worse than they really were. One advantageous aspect of Schwanenflugel and Rey's (1986) experiment was that in addition to selfratings, participants had to obtain scores on Spanish and English reading comprehension tests that did not differ by more than $19 \%$. Methods such as these may allow bilinguals to be screened more carefully.

Although certain modifications may be useful, the proficiency of bilingual participants has been the subject of a long-standing debate and remains a difficult problem when such studies are conducted. Francis (1999) has discussed the wide range of terminology that has been used to define bilinguals and has concluded that an intermediate definition proposed by Grosjean (1992, cited in Fran- cis, 1999) may be the most beneficial: "Bilingualism is the regular use of two (or more) languages, and bilinguals are those people who need and use two (or more) languages in their everyday lives" (p. 51). It has also been suggested that since it is often difficult to find bilinguals who are equally balanced, researchers should present adequate information regarding their bilingual participants. Grosjean (1998) has suggested that some experimenters may be most concerned with reading ability, others with language use and speaking skills, whereas some feel that language stability (whether the bilingual is still acquiring their L2 or not) should be emphasized. Therefore, since the information often obtained and the way in which bilinguals are assessed may be vastly different, it is possible that "we have very different bilinguals in the studies published" (Grosjean, 1998, p. 9). This may very well be one of the factors contributing to the diverse range of priming effects reported in semantic-priming studies. As a way of coping with this challenge, it has been suggested that researchers include information not only on biographical data, but also on language history as well. Therefore, it will be useful to know the age at which each language has been learned, as well as the way in which it was learned (type of educational system, etc.). In addition to proficiency ratings in the four skill areas (reading, writing, speaking, and listening), language stability and when and where each language has been used most may also be information that is advantageous to researchers (Grosjean, 1998). Although these recommendations may seem superfluous and difficult to carry out, the benefits of such diligence will give bilingual research more consistency. Finally, researchers are encouraged to use an online measure of proficiency or dominance as an assessment tool when examining language background. Picture-naming or translation tasks may be useful in this regard.

Cognate status. Additional methodological concerns in much of the semantic-priming literature have to do with the word stimuli that have been chosen. One of the areas in which variation has been found to occur deals with the use of cognates, or words that are similar in spelling, pronunciation, and meaning across languages (e.g., music and musica). Since these words are so similar in both languages, it is important that they be excluded from word stimuli if automatic and pure priming effects are being investigated. Fortunately, most researchers have explicitly stated that no cognates have been used in their studies (Frenck \& Pynte, 1987; Keatley et al., 1994; Kirsner et al., 1984; Larsen et al., 1994; Schwanenflugel \& Rey, 1986; Williams, 1994), but others have not mentioned whether they were included or not (Grainger \& Beauvillain, 1988; Keatley \& de Gelder, 1992; Meyer \& Ruddy, 1974).

Masking effects. Another methodological difference observed in some of the studies is the visibility of the prime word. Although most researchers have chosen to use unmasked priming paradigms, a couple of studies included a masked design (de Groot \& Nas, 1991, Experiment 3, for associative word pairs; Williams, 1994, Experiment 1a). Since masking often results in decreased visibility of the prime word, the implementation of this type of design may be beneficial, in that it may minimize 
the use of strategic processes by participants. The priming effects measured across these cross-language priming studies may also differ because they were determined using different types of word stimuli as a control. Simply stated, some researchers have measured priming effects by comparing related word pairs with unrelated word pairs (Chen \& Ng, 1989; Grainger \& Beauvillain, 1988; Keatley \& de Gelder, 1992; Keatley et al., 1994; Kirsner et al., 1984; Larsen et al., 1994; Meyer \& Ruddy, 1974; Tzelgov \& Eben-Ezra, 1992; Williams, 1994), whereas others have chosen neutral targets as the control (Keatley et al., 1994, Experiment 1; Schwanenflugel \& Rey, 1986). Meanwhile, Frenck and Pynte (1987) examined response times to related prime-target pairs and how they compared with the same target words when they were not preceded by a prime.

Word frequency and word length across languages. As was discussed in the section on monolingual priming, frequency and length of words can be influential in altering priming effects if these variables are not controlled for when the experiment is designed. In many of the semanticpriming studies under review, an attempt has been made to keep these factors constant; however, this has not been the case for every study. Some authors have specifically stated that words used in both languages had fairly equivalent mean letter lengths (Frenck \& Pynte, 1987; Grainger \& Beauvillain, 1988; Keatley \& de Gelder, 1992; Keatley et al., 1994; Kirsner et al., 1984; Meyer \& Ruddy, 1974). Chen and $\mathrm{Ng}$ (1989) mentioned that they controlled for word length in English, but due to the fact that Chinese characters were used, it was impossible to equate and compare both languages on length. Others have stated that "they attempted to control for word length, but were only partially successful" (Schwanenflugel \& Rey, 1986, p. 608), whereas for a couple of studies, there was no mention of whether these variables were monitored or not (Larsen et al., 1994; Tzelgov \& Eben-Ezra, 1992).

Experimental design differences. An analysis of some of the methodological factors that are responsible for allowing participants to utilize strategic processes reveals some of the most diverse differences in experimental design. For example, the SOA length implemented by many of the researchers ranged anywhere from $0 \mathrm{msec}$ to $4.5 \mathrm{sec}$. Meyer and Ruddy (1974) and Kirsner et al. (1984) chose to use a double lexical decision task, where both the prime and the target were presented simultaneously, resulting in an SOA of $0 \mathrm{msec}$. In a majority of the experiments, the tendency has been to use an SOA ranging from 200 to $300 \mathrm{msec}$ (Chen \& Ng, 1989; Grainger \& Beauvillain, 1988; Keatley \& de Gelder, 1992; Keatley et al., 1994; Larsen et al., 1994; Schwanenflugel \& Rey, 1986). However, there still have been a significant number of studies that have contained longer SOAs ranging from $500 \mathrm{msec}$ on up (Frenck \& Pynte, 1987; Grainger \& Beauvillain, 1988; Keatley et al., 1994; Tzelgov \& Eben-Ezra, 1992; Williams, 1994). SOAs of this length may raise problems, in that they allow participants to utilize expectancy strategies. A long SOA may allow participants to translate the prime into the alternate language, which can indicate that automatic processing of both languages is not being ac- curately measured. However, it must be mentioned that several authors have included a long and a short SOA, in order to see whether there were differences in the size of the priming effect (Grainger \& Beauvillain, 1994, Experiment 1; Keatley et al., 1994; Tzelgov \& Eben-Ezra, 1992). Adding to the confusion is the fact that Grainger and Beauvillain reported significant priming only in the L2-L1 direction at the long SOA $(750 \mathrm{msec})$, whereas data from Keatley et al. indicated nonsignificant priming effects for both directions at both the short and the long SOAs (250 and 2,000 msec, respectively). Meanwhile, Tzelgov and Eben-Ezra revealed robust priming effects that were collapsed across SOA length for both directions.

Relatedness proportion and nonword ratio in bilingual priming. An analysis of additional methodological factors, including RP and NWR, has also revealed a large range of values. The suggested NWR of .50 was used by Schwanenflugel and Rey (1986); however, in other studies, NWR has been just slightly above this recommended value (Keatley \& de Gelder, 1992; Keatley et al., 1994; Kirsner et al., 1984). A few studies have not appeared to be as successful, with NWRs ranging from .67 to .75 (Chen \& Ng, 1989; Frenck \& Pynte, 1987; Kirsner et al., 1984, Experiment 5; Meyer \& Ruddy, 1974; Tzelgov \& Eben-Ezra, 1992; Williams, 1994). It should also be noted that the study conducted by Larsen et al. (1994) did not include any nonwords, since a pronunciation task was chosen for the experiment.

An analysis of RP has also shown values that were very high, indicating that strategic processes may have been employed by participants. Grainger and Beauvillain (1988), Keatley and de Gelder (1992), and Keatley et al. (1994) all made extensive efforts to maintain low RPs of $.167, .25$, and .25 , respectively. However, there were also those studies in which a high RP of .67 was used (Chen \& Ng, 1989; Frenck \& Pynte, 1987).

One last issue of concern that may affect the interpretation of reported priming effects is the mean response times for the related cross-language word pairs. Response times approaching and/or reaching 1,000 msec (Chen \& Ng, 1989; Kirsner et al., 1984; Meyer \& Ruddy, 1974) may indicate that the participants were translating the primes. This may have been one of the factors that was partially responsible for the robust priming effects reported by Chen and $\mathrm{Ng}$.

Summary. In conclusion, the semantic-priming experiments that have been conducted are useful in that they attempt to explain the way in which a variety of languages (romance languages, languages using different alphabets and characters, etc.) may be represented in memory. However, it is apparent that there are many methodological issues of concern that need to be taken into consideration when this type of experiment is designed. Furthermore, many of the factors that have been discussed may help shed some light on why current priming studies have revealed such a wide range of inconsistent results. In the section that follows, cross-language translation priming studies will be examined. Although these studies tend to be more recent, they are also plagued by some of the same methodological issues of concern. 


\section{Translation Priming Across Languages}

In addition to the cross-language semantic-priming studies, there are also nearly one dozen translationpriming studies that have been conducted in the past decade. In accordance with the previous studies noted earlier, translation-priming studies involve the presentation of a prime in one language and a target in a different language. However, instead of semantically related word pairs, words and their respective translations compose the word pairs in this paradigm. For example, a typical trial would present the prime word cat followed by the target word gato (the Spanish translation of cat). However, in the same vein as many of the semantic-priming studies, the methodological issues of concern that were previously discussed are also prevalent in this body of literature. Below, various parameters that may influence the outcome of translation-priming studies and suggestions for avoiding various methodological "pitfalls" in this area of research will be given.

Language proficiency. Once again, the proficiency of bilinguals participating in these studies often has not been fully explained at times. Some participants have been described as acquiring their L2 before adolescence (Altarriba, 1992; Gollan, Forster, \& Frost, 1997; Jin, 1990; Keatley et al., 1994), whereas others began to learn the L2 either during or after adolescence (Chen \& Ng, 1989; Grainger \& Frenck-Mestre, 1998; Jiang, 1999; Jiang \& Forster, 2001; Williams, 1994). However, the lack of information given regarding participants' language history and background is evident in a statement from one study, which described all the participants as being "reasonably good" at comprehending English (de Groot \& Nas, 1991). Again, the use of performance measures as a screening device may aid in the ability to describe proficiency and dominance for bilingual participants.

Selection of word stimuli and masking. Although an analysis of the word stimuli used in these experiments reveals many of the same problems as those already observed in the priming literature, one advantage of the translation-priming studies is that they are more recent and, therefore, attempts have been made to regulate many potentially problematic factors (see Appendix B for a review of cross-language translation-priming experiments). For example, all of these studies have used one common control - unrelated prime-target word pairs - when priming effects were calculated. In addition, all the studies have reported that cognates were not included in word stimuli, except for those studies in which the purpose was to examine differences between cognates and noncognates (de Groot \& Nas, 1991; Gollan et al., 1997). Another experimental manipulation that is more prevalent in this body of literature is the use of masked priming techniques. Whereas only two semantic-priming studies have included a masked procedure (de Groot \& Nas, 1991, Experiment 3; Williams, 1994, Experiment 1a), the use of a mask in translation priming has been used by more authors (de Groot \& Nas, 1991; Gollan et al., 1997; Grainger \& Frenck-Mestre, 1998; Jiang, 1999; Jiang \& Forster, 2001; Williams, 1994). In most studies, the forward masked priming procedure (or a variation of this procedure) first introduced by Forster and Davis (1984) has been used. In this paradigm, each trial begins with a fixation and is followed by the mask, which usually appears as a row of number signs (\#\#\#\#\#) and remains on the screen for 450 or $500 \mathrm{msec}$. The prime word then appears for $50 \mathrm{msec}$ (100 msec in some of the bilingual studies) and is then replaced by the target word.

Word frequency and word length. An examination of the average length and frequency of word stimuli used in translation priming reveals that in some of the studies, an attempt has been made to control for these variables (Altarriba, 1992; Gollan et al., 1997; Grainger \& FrenckMestre, 1998; Jiang, 1999; Jiang \& Forster, 2001; Keatley \& de Gelder, 1992; Keatley et al., 1994; Williams, 1994). However, several other studies have not mentioned whether length and frequency were monitored (de Groot \& Nas, 1991; Jin, 1990), whereas one study discussed only the control of word length (Chen \& Ng, 1989). Clearly, for reasons noted earlier, both of these variables should be controlled, if possible, when one works with crosslanguage stimuli.

Stimulus onset asynchrony. With regard to some of the factors that are capable of allowing strategic processes to develop, a comparison of the SOA length used in the translation-priming studies indicates that SOA length has been kept very short. Multiple studies have used an SOA of 50 msec (Gollan et al., 1997; Jiang, 2001; Williams, 1994), whereas de Groot and Nas (1991) and Grainger and Frenck-Mestre (1998) chose SOA lengths of 60 and $56 \mathrm{msec}$, respectively. The only SOA of extreme length, $1,000 \mathrm{msec}$, is observed in Altarriba's (1992) study; however, a short SOA of $200 \mathrm{msec}$ was also included in this study so that a comparison between SOA lengths could be made. As was expected, the data produced by the varying SOA lengths did indicate larger priming effects at the longer SOA.

Relatedness proportion and nonword ratio. An analysis of NWR and RP in the translation-priming literature shows a wide range of ratios that often deviate from ideal values. Four studies revealed NWRs that hovered around the suggested .50 value (Gollan et al., 1997; Keatley \& de Gelder, 1992; Keatley et al., 1994; Williams, 1994), whereas all the other studies appeared to have NWRs that were either lower or higher than .50. The calculated RPs for most of these studies showed relatively high values, ranging from .50 to .67 (Chen \& Ng, 1989; de Groot \& Nas, 1991; Gollan et al., 1997; Grainger \& Frenck-Mestre, 1998; Jiang, 1999; Jiang \& Forster, 2001; Jin, 1990; Williams, 1994). However, the studies conducted by Altarriba (1992), Keatley and de Gelder (1992), and Keatley et al. (1994) were successful in maintaining low RPs of $.33, .25$, and .25 , respectively.

Summary. Therefore, it is evident that since many of these methodological issues of concern show such diverse values, it is not surprising that robust translation-priming effects in the L1-L2 and L2-L1 direction have been observed in some studies (Chen \& Ng, 1989; Jin, 1990; Keatley \& de Gelder, 1992; Jiang, 1999, Experiment 1; Keatley et al., 1994), but not in others (Gollan et al., 1997; Jiang \& Forster, 2001, Experiment 2). In addition, in some studies, 
only priming for noncognates in the L1-L2 direction has been examined (de Groot \& Nas, 1991; Williams, 1994), whereas others have been concerned only with priming in the L2-L1 direction (Grainger \& Frenck-Mestre, 1998; Jiang \& Forster, 2001). However, the fact that L2-L1 priming yielded nonsignificant priming effects for several studies (Altarriba, 1992, at an SOA length of $200 \mathrm{msec}$; Gollan et al., 1997, Experiments 2 and 4; Grainger \& Frenck-Mestre, 1998; Jiang, 1999, Experiment 2; Jiang $\&$ Forster, 2001) has led some to specifically examine the processing behind asymmetrical priming effects in a very creative and interesting way (see Finkbeiner, Forster, Nicol, \& Nakamura, 2004; Jiang \& Forster, 2001).

In conclusion, one can see that many of the translationpriming studies appear to have some of the same methodological issues of concern that were observed in the cross-language semantic-priming studies. Once many of the methodological issues that have been previously discussed are monitored and controlled, future translationpriming studies should be capable of providing more insight into the way in which a bilingual represents his or her two languages.

\section{Conclusions}

In an attempt to interpret some of the overall observations that can be made regarding Appendices A and B, some trends appear to emerge. First, it might be the case that the asymmetry that appears to be stronger for translation priming, in comparison with semantic priming, may be due to the use of shorter SOAs and more tightly constrained presentation rates and RPs than in the semanticpriming literature. For example, the work of Williams (1994, Experiment 2b) indicated significant priming (33 msec) in the L1-L2 direction, under well-constrained conditions (e.g., 50-msec SOA, etc.). In this article, a variety of language combinations also were examined, and it was concluded that priming was similar across various language groupings. However, priming in the L2-L1 direction was not investigated. Second, as one might expect from the monolingual literature, an increase in SOA also appears to be correlated with an increase in the magnitude of semantic priming. For example, Grainger and Beauvillain's (1988) data for a short SOA (150 msec) indicated no evidence of cross-language priming for English-French bilinguals. In contrast, the data provided by Williams (1994, Experiment 1a), using an SOA of $728 \mathrm{msec}$, indicated a positive 34-msec effect in the L1-L2 direction. Thus, although systematic increases in SOA and RP and increased visibility of prime words all served to produce more priming of both kinds (semantic and translation), it also appears that those effects were moderated, at least in part, by more strategic and less automatic processing.

The study of priming effects for semantically related word pairs and translation word pairs is important for various reasons. First, the methodology used is widely accepted as one that leads to the discovery of the representational structure of language in human memory. Second, the issue investigated in the field has to do with a circumstance that is common among a majority of people in the world - that of knowing and using more than one language to communicate. Third, work in this general area has led to the development of research tools that have been used to uncover general language-processing mechanisms that apply to monolingual populations as well (see, e.g., Altarriba, Kambe, Pollatsek, \& Rayner, 2001; Altarriba, Kroll, Sholl, \& Rayner, 1996; Altarriba \& Soltano, 1996), since cross-language stimuli may assist in the examination of basic levels of language representation (e.g., semantics) while others are held constant (e.g., lexicality). Fourth, the priming methodology is widely held to be one that can be used to investigate the automaticity of language processing - an approach that is most informative when models of language representation and processing are derived. Finally, investigations of this nature are pragmatic and relatively easy to implement, indicating that the refinement of this type of method and careful analysis of the methodological issues contained in this area of research are extremely important to the promotion of this type of work across cultures.

\section{Recommendations for Future Research}

As researchers continue to use semantic- and translationpriming paradigms to describe the representational structure of multiple languages in memory, the following methodological recommendations should be followed.

1. Test explicitly for language proficiency in the language skill being manipulated in the protocol. There is a need to include more information on the language history of bilingual participants and, perhaps, to conduct studies in which variables are manipulated within participants. The difficulty with generalizing across the reported studies lies in the variability of the participants and of their mode of language acquisition and the varying age of acquisition across the participants. Furthermore, the use of actual tests of language proficiency that are aligned with the variables under investigation (e.g., reading tests for visual reading studies, etc.), along with comprehensive language history surveys, should be adopted. These measures should also be developed so as to allow for the identification of which language is dominant for a given speaker. Once more comprehensive proficiency data have been collected on participants, it is possible that certain language background factors can be entered as a covariate, so that one can examine how the results covary with dominance.

2. Match stimuli across paradigms within the same experiment. If both lexical decision tasks and pronunciation tasks are being used, the same stimuli should also be used. Varying the items used across paradigms within a given series of experiments also adds variability in terms of items. This issue leads to the suggestion that item analyses should also be a common feature of these types of investigations.

3. Eliminate cognates and homographic noncognates if they are not the focus of the research question. Researchers should strive to eliminate the use of cognates or homographic noncognates when conducting semantic- and translation-priming research across languages, unless these are the very items that are under investigation. An examination of various word lists that have been used 
across this literature indicates that these word types have been included among other noncognate items without reference to their possible confounding effects.

Conversely, the use of different item types in terms of word class (e.g., emotion words vs. concrete words vs. abstract words) is a potentially fruitful area of investigation, since this type of study would help to delimit certain models of bilingual processing. That is, given that hierarchical models (e.g., Kroll \& Stewart, 1994) can shed light on the representation of words that share translation equivalents and that other distributed models (e.g., de Groot, 1993) describe representation for other word types as well, the use of different word classes in cross-language investigations can either support or fail to support a given model's predictions. Therefore, the use of different word types can help to discriminate between models and, perhaps, to develop new ones that are more comprehensive in nature.

Furthermore, when lexical decision tasks are used to examine bilingual memory representation, it is important that two types of nonwords be created. It would be advantageous to have one set of nonwords that is formed by changing one letter in words in the L1, which will result in nonwords that are pronounceable in the L1. However, nonwords that are phonologically possible in the L2 should also be included. This will result in the creation of nonwords that are not biased toward one language.

4. Use a consistent baseline across experiments within a series. Clearly, a variety of baselines have been used throughout this literature, ranging from neutral conditions to unrelated word conditions. This difference across experiments, sometimes within a single article, also makes it difficult to generalize priming effects across the general population. The use of a consistent baseline across a set of experiments is recommended. Truly neutral baselines are often difficult to achieve. One recommendation here is to counterbalance the items used so that items appear in both related and unrelated conditions across prime-target pairs. At the very least, the same items will be used in both of the primary conditions of interest.

5. Word frequency and word length should be controlled across conditions within an experiment. Researchers in this area of investigation are typically concerned with word frequency and word length and their impact on performance within priming experiments. If orthographies are similar across languages, the number of characters in words should be equated across experimental and control conditions. For other types of languages that are nonalphabetic, for example, controlling for syllable number or length, or perhaps bigram frequency, might be a possibility. Participants' response times can often be influenced by the inclusion of words that are either too long or too short, and if an item and its corresponding control differ dramatically in length, this variable could serve to moderate the magnitude of the priming effect. Word frequency - printed word frequency — is also an important factor. If stimuli are presented visually, a word frequency count for words in print should be consulted, regardless of the language under investigation. Many different corpora exist in different languages. However, caution should be exercised when consulting these norms as there may be dialectical differences that should be considered before a specific database is used (e.g., Spanish spoken in Spain vs. Spanish spoken in Puerto Rico). In addition, one may also want to take phonotactic factors into consideration, which can be used to examine the phonological configurations that are common in a specific language. Since this variable may influence word retrieval it may be important to know the extent to which two languages overlap in phonetic combinations and/or word onsets.

6. The SOA should be kept short if automatic processing is under examination. The length of the $\mathrm{SOA}$, as described previously, could moderate the strength of the priming effect, as well as influencing the degree to which strategic processing occurs. Short SOAs, those under $200 \mathrm{msec}$, are less likely to produce relatedness checking or other postlexical processing strategies than are SOAs that are longer in duration.

7. The nonword ratio should be controlled in order to minimize the use of strategic processing. If participants can develop expectancies for the nature of an item, given a previous trial, these expectancies can contribute to an overall strategy for responding to words or nonwords. A nonword ratio of approximately .50 would help to minimize bias in either direction and would increase the uncertainty for subsequent trials in a given stimulus list.

8. The relatedness proportion within a list should be kept low in order to minimize the use of an expectancy strategy by participants. When the proportion of related word-word trials is high, as compared with the number of overall word-word trials, participants may develop a strategy for responding that might link positive "word" responses to related word pairs. In order to minimize the use of this particular type of expectancy strategy, it is suggested that this proportion be kept as low as possible, while still providing enough data per participant to lead to reasonable analyses.

9. Use a masking procedure to minimize the use of predictive strategies by participants. The use of masked priming experiments serves to greatly minimize the use of predictive strategies, since participants typically cannot consciously identify a particular word prime. However, various features of the word, such as its semantic or conceptual representation, influence performance on wordtarget trials. Thus, it is recommended that a given set of stimuli and participants be tested in both a masked and an unmasked condition within a single experiment with the proper counterbalancing of items.

10. Choose a presentation format (single vs. double $v$ s. sequential) that would minimize relatedness checking strategies across primes and targets. As was noted in the present review, procedures have varied from double lexical decision trials, to single lexical decision trials, to the naming of targets following the silent reading of primes. Perhaps a method that should be considered more carefully within this area of research involves a sequential presentation of items requiring a response to each and every one (see, e.g., McNamara \& Altarriba, 1988). This method discourages the coupling of primes and targets into pairs, thereby minimizing the overt linking of related primes and targets. It has been successfully used to inves- 
tigate direct priming and mediated priming in studies of monolingual speakers.

11. When cross-language effects are examined, include within-language conditions, as well as a comparison. In some instances, within the studies reviewed here, researchers examined processing across language in a single direction (e.g., L1-L2 or L2-L1). These studies present only half of the picture, at best, and their design does not allow for the full specification of data that might address representational issues with regard to the development of bilingual memory models. Researchers should examine both processing directions, as well as possibly including within-language demonstrations (see de Groot \& Nas, 1991; Gollan et al., 1997; and Jiang, 2001, as good examples). The latter recommendation would assure investigators that the items do indeed produce priming, if only within languages, as opposed to across languages.

12. Strive to test a particular set of hypotheses across a specific set of languages, prior to working across varying languages within a single set of studies. Clearly, part of the variability in results reported across the studies reviewed here lies with the use of many different languages. Although one would expect that the basic processes that produce priming effects would influence processing in the same way, regardless of language per se, this variability, coupled with the many issues addressed above, adds to the overall difficulty in generalizing basic findings. Although researchers capitalize on their resources in terms of the availability of language participants of a particular background, until a given language or set of languages has been examined across a variety of settings and paradigms, it will remain difficult to draw strong conclusions regarding the existence of semantic or translation priming across any languages at all.

\section{AUTHOR NOTE}

Portions of this work were presented at the VIII Conference on Applied Linguistics (Spanish and Other Languages), Universidad de las Américas, Cholula, Puebla, Mexico, as well as at the XIII Conference of the European Society for Cognitive Psychology (ESCOP), Granada, Spain. We thank Roberto R. Heredia and an anonymous reviewer for their insightful comments on an earlier version of the manuscript. Correspondence related to this work can be sent to J. Altarriba, Department of Psychology, University at Albany, SUNY, Social Sciences 369, Albany, NY12222 (e-mail: ja087@albany.edu).

\section{REFERENCES}

Altarriba, J. (1992). The representation of translation equivalents in bilingual memory. In R. J. Harris (Ed.), Cognitive processing in bilinguals (pp. 157-174). Amsterdam: Elsevier.

Altarriba, J. (2003). Does cariño equal "liking"? A theoretical approach to conceptual nonequivalence between languages. International Journal of Bilingualism, 7, 305-322.

Altarriba, J., Kambe, G., Pollatsek, A., \& Rayner, K. (2001). Semantic codes are not used in integrating information across eye fixations: Evidence from fluent Spanish-English bilinguals. Perception \& Psychophysics, 63, 875-890.

Altarriba, J., Kroll, J., Sholl, A., \& Rayner, K. (1996). The influence of lexical and conceptual constraints on reading mixed-language sentences: Evidence from eye-fixation and naming times. Memory \& Cognition, 24, 477-492.

Altarriba, J., \& Soltano, E. G. (1996). Repetition blindness and bilingual memory: Token individuation for translation equivalents. Memory \& Cognition, 24, 700-711.

Balota, D. A., \& Chumbley, J. I. (1984). Are lexical decisions a good measure of lexical access? The role of word frequency in the neglected decision stage. Journal of Experimental Psychology: Human Perception \& Performance, 10, 340-357.

Balota, D. A., \& Chumbley, J. I. (1985). The locus of word frequency effects in the pronunciation task: Lexical access and/or production? Journal of Memory \& Language, 24, 89-106.

Balota, D. A., \& Chumbley, J. I. (1990). Where are the effects of frequency in visual word recognition tasks? Right where we said they were! Comment on Monsell, Doyle, and Haggard (1989). Journal of Experimental Psychology: General, 119, 231-237.

Battig, W. F., \& Montague, W. E. (1969). Category norms for verbal learning items in 56 categories: A replication and extension of the Connecticut category norms. Journal of Experimental Psychology Monographs, 80(3, Pt. 2), 1-45.

Bhatia, T. K., \& Ritchie, W. C. (2004). Bilingualism in South Asia. In T. K. Bhatia \& W. C. Ritchie (Eds.), The handbook of bilingualism (pp. 780-807). Malden, MA: Blackwell.

Chen, H., \& NG, M. (1989). Semantic facilitation and translation priming effects in Chinese-English bilinguals. Memory \& Cognition, 17, 454-462.

Chumbley, J. I., \& Balota, D. A. (1984). A word's meaning affects the decision in lexical decision. Memory \& Cognition, 12, 590-606.

Collins, A. M., \& LofTus, E. F. (1975). A spreading activation theory of semantic processing. Psychological Review, 82, 407-428.

Collins, A. M., \& Quillian, M. R. (1969). Retrieval time from semantic memory. Journal of Verbal Learning \& Verbal Behavior, 8, 240-247.

Cristoffanini, P., Kirsner, K., \& Milech, D. (1986). Bilingual lexical representation: The status of Spanish-English cognates. Quarterly Journal of Experimental Psychology, 38A, 367-393.

DE Groot, A. M. B. (1984). Primed lexical decision: Combined effects of the proportion of related prime-target pairs and the stimulus-onset asynchrony of prime and target. Quarterly Journal of Experimental Psychology, 36A, 253-280.

DE GRoOT, A. M. B. (1993). Word-type effects in bilingual processing tasks: Support for a mixed-representational system. In R. Schreuder \& B. Weltens (Eds.), The bilingual lexicon (pp. 27-51). Amsterdam: Benjamins.

DE GRoot, A. M. B., \& NAS, G. L. J. (1991). Lexical representation of cognates and noncognates in compound bilinguals. Journal of Memory \& Language, 30, 90-123.

Dufour, R., \& Kroll, J. F. (1995). Matching words to concepts in two languages: A test of the concept mediation model of bilingual representation. Memory \& Cognition, 23, 166-180.

EDWARDS, J. V. (2004). Foundations of bilingualism. In T. K. Bhatia \& W. C. Ritchie (Eds.), The handbook of bilingualism (pp. 7-31). Malden, MA: Blackwell.

Finkbeiner, M., Forster, K., Nicol, J., \& NaKamura, K. (2004). The role of polysemy in masked semantic and translation priming. Journal of Memory \& Language, 51, 1-22.

Forster, K. I., \& DaVIS, C. (1984). Repetition priming and frequency attenuation in lexical access. Journal of Experimental Psychology: Learning, Memory, \& Cognition, 10, 680-698.

Fox, E. (1996). Cross-language priming from ignored words: Evidence for a common representational system in bilinguals. Journal of Memory \& Language, 35, 353-370.

FRANCIS, W. (1999). Cognitive integration of language and memory in bilinguals: Semantic representation. Psychological Bulletin, 125, 193-222.

Frenck, C., \& Pynte, J. (1987). Semantic representation and surface forms: A look at across language priming in bilinguals. Journal of Psycholinguistic Research, 16, 383-396.

Gollan, T. H., Forster, K. I., \& Frost, R. (1997). Translation priming with different scripts: Masked priming with cognates and noncognates in Hebrew-English bilinguals. Journal of Experimental Psychology: Learning, Memory, \& Cognition, 23, 1122-1139.

Grainger, J., \& Beauvillain, C. (1988). Associative priming in bilinguals: Some limits of interlingual facilitation effects. Canadian Journal of Psychology, 42, 261-273.

Grainger, J., \& FrenCK-Mestre, C. (1998). Masked priming by translation equivalents in proficient bilinguals. Language \& Cognitive Processes, 13, 601-623.

Grosjean, F. (1998). Studying bilinguals: Methodological and conceptual issues. Bilingualism: Language \& Cognition, 1, 131-149. 
Hutchison, K. A., NeEly, J. H., \& Johnson, J. D. (2001). With great expectations, can two "wrongs" prime a "right"? Journal of Experimental Psychology: Learning, Memory, \& Cognition, 27, 1451-1463.

JIANG, N. (1999). Testing processing explanations for the asymmetry in masked cross-language priming. Bilingualism: Language \& Cognition, 2, 59-75.

JiAnG, N., \& Forster, K. I. (2001). Cross-language priming asymmetries in lexical decision and episodic recognition. Journal of Memory \& Language, 44, 32-51.

JIN, Y. (1990). Effects of concreteness on cross-language priming in lexical decisions. Perceptual \& Motor Skills, 70, 1139-1154.

Keatley, C. [W.], \& DE Gelder, B. (1992). The bilingual primed lexical decision task: Cross-language priming disappears with speeded responses. European Journal of Cognitive Psychology, 4, 273-292.

Keatley, C. W., SpinKs, J. A., \& DE Gelder, B. (1994). Asymmetrical cross-language priming effects. Memory \& Cognition, 22, 70-84.

Kirsner, K., Smith, M. C., Lockhart, R. S., King, M. L., \& Jain, M. (1984). The bilingual lexicon: Language-specific units in an integrated network. Journal of Verbal Learning \& Verbal Behavior, 23, 519-539.

Kolers, P. A. (1978). On the representation of experience. In D. Gerver \& H. W. Sinaiko (Eds.), Language interpretation and communication (pp. 245-258). New York: Plenum.

Kolers, P. A. (1979). Reading and knowing. Canadian Journal of Psychology, 33, 106-117.

Kroll, J. F., \& StewART, E. (1994). Category interference in translation and picture naming: Evidence for asymmetric connections between bilingual memory representations. Journal of Memory \& Language, 33, 149-174.

KuČERA, H., \& FrANCIS, W. N. (1967). Computational analysis of presentday American English. Providence, RI: Brown University Press.

Larsen, J. D., Fritsch, T., \& Grava, S. (1994). A semantic priming test of bilingual language storage and the compound vs. coordinate bilingual distinction with Latvian-English bilinguals. Perceptual \& Motor Skills, 79, 459-466.

McCormack, P. D. (1976). Language as an attribute of memory. Canadian Journal of Psychology, 30, 238-248.

McCORMACK, P.D.(1977). Bilingual linguistic memory: The independenceinterdependence issue revisited. In P. A. Hornby (Ed.), Bilingualism: Psychological, social, and educational implications (pp. 57-66). New York: Academic Press.

McNamara, T. P., \& Altarriba, J. (1988). Depth of spreading activation revisited: Semantic mediated priming occurs in lexical decisions. Journal of Memory \& Language, 27, 545-559.

McNamara, T. P., \& Holbrook, J. B. (2003). Semantic memory and priming. In A. F. Healy \& R. W. Proctor (Eds.), Handbook of psychology: Experimental psychology (Vol. 4, pp. 447-474). New York: Wiley.

MeYer, D. E., \& Ruddy, M. G. (1974, April). Bilingual word recogni- tion: Organization and retrieval of alternative lexical codes. Paper presented at the meeting of the Eastern Psychological Association, Philadelphia.

Meyer, D. E., \& Schvaneveldt, R. W. (1971). Facilitation in recognizing pairs of words: Evidence of a dependence between retrieval operations. Journal of Experimental Psychology, 90, 227-234.

Meyer, D. E., Schvaneveldt, R. W., \& Ruddy, M. G. (1975). Loci of contextual effects on visual word recognition. In P. M. A. Rabbitt \& S. Dornic (Eds.), Attention and performance $V$ (pp. 98-118). New York: Academic Press.

Monsell, S., Doyle, M. C., \& Haggard, P. N. (1989). Effects of frequency on visual word recognition tasks: Where are they? Journal of Experimental Psychology: General, 118, 43-71.

NeEly, J. H. (1977). Semantic priming and retrieval from lexical memory: Roles of inhibitionless spreading activation and limited-capacity attention. Journal of Experimental Psychology: General, 106, 226-254.

NeEly, J. H. (1991). Semantic priming effects in visual word recognition: A selective review of current findings and theories. In D. Besner \& G. W. Humphreys (Eds.), Basic processes in reading: Visual word recognition (pp. 264-336). Hillsdale, NJ: Erlbaum.

NeEly, J. H., \& KaHAN, T. A. (2001). Is semantic activation automatic? A critical re-evaluation. In H. L. Roediger III, J. S. Nairne, I. Neath, \& A. M. Surprenant (Eds.), The nature of remembering: Essays in honor of Robert G. Crowder (pp. 69-93). Washington, DC: American Psychological Association.

Neely, J. H., Keefe, D. E., \& Ross, K. L. (1989). Semantic priming in the lexical decision task: Roles of prospective prime-generated expectancies and retrospective semantic matching. Journal of Experimental Psychology: Learning, Memory, \& Cognition, 15, 1003-1019.

Ratcliff, R., \& McKoon, G. (1988). A retrieval theory of priming in memory. Psychological Review, 95, 385-408.

RAVEH, M. (2002). The contribution of frequency and semantic similarity to morphological processing. Brain \& Language, 81, 312-325.

Sánchez-Casas, R. M., Davis, C. W., \& García-Albea, J. E. (1992). Bilingual lexical processing: Exploring the cognate/non-cognate distinction. European Journal of Cognitive Psychology, 4, 293-310.

SCHWANENFlugel, P. J., \& REY, M. (1986). Interlingual semantic facilitation: Evidence for a common representational system in the bilingual lexicon. Journal of Memory \& Language, 25, 605-618.

TABouret-Keller, A. (2004). Bilingualism in Europe. In T. K. Bhatia \& W. C. Ritchie (Eds.), The handbook of bilingualism (pp. 662-688). Malden, MA: Blackwell.

Tzelgov, J., \& Eben-Ezra, S. (1992). Components of the betweenlanguage semantic priming effect. European Journal of Cognitive Psychology, 4, 253-272.

WiLliams, J. N. (1994). The relationship between word meanings in the first and second language: Evidence for a common, but restricted, semantic code. European Journal of Cognitive Psychology, 6, 195-220. 


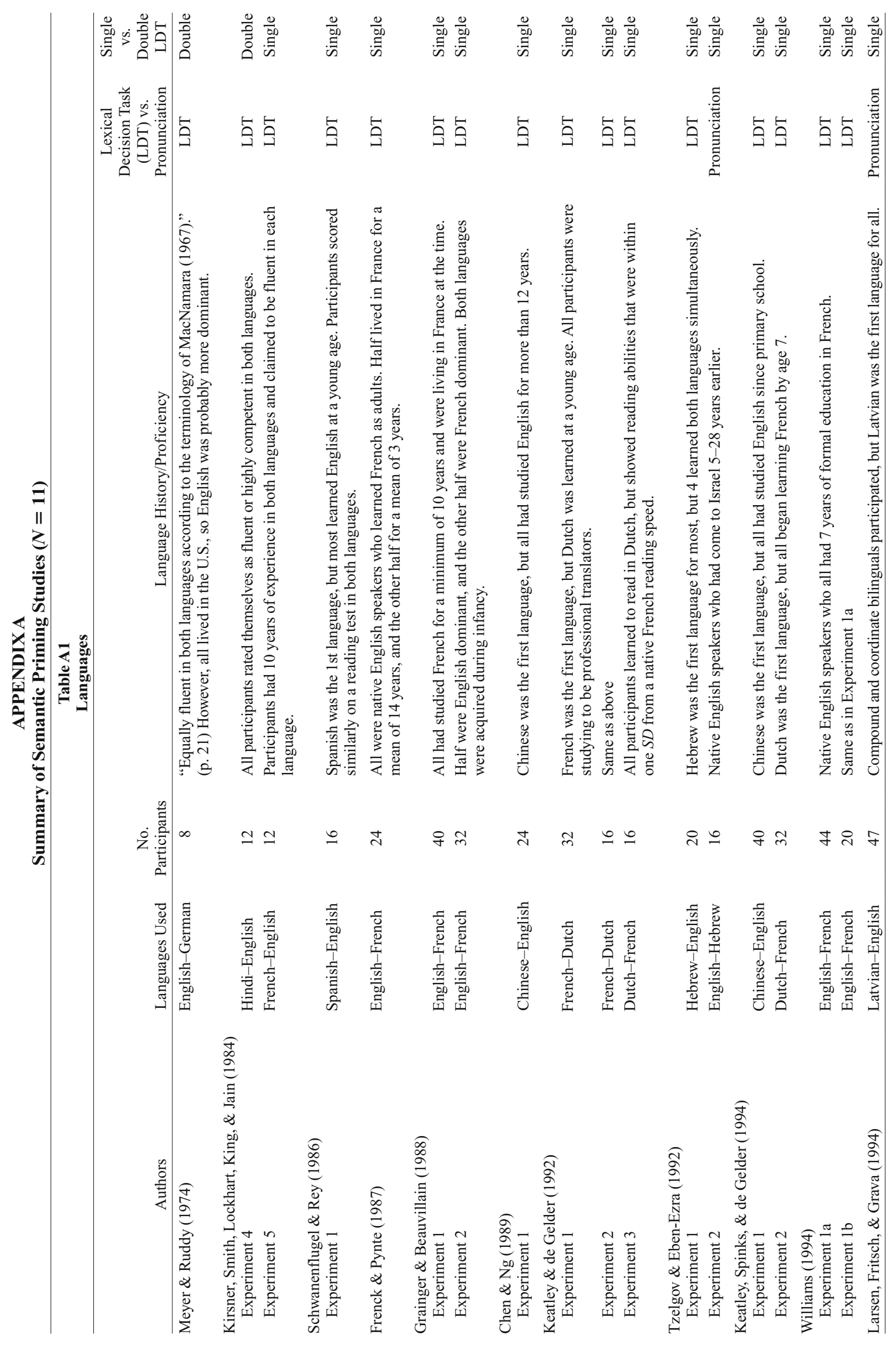




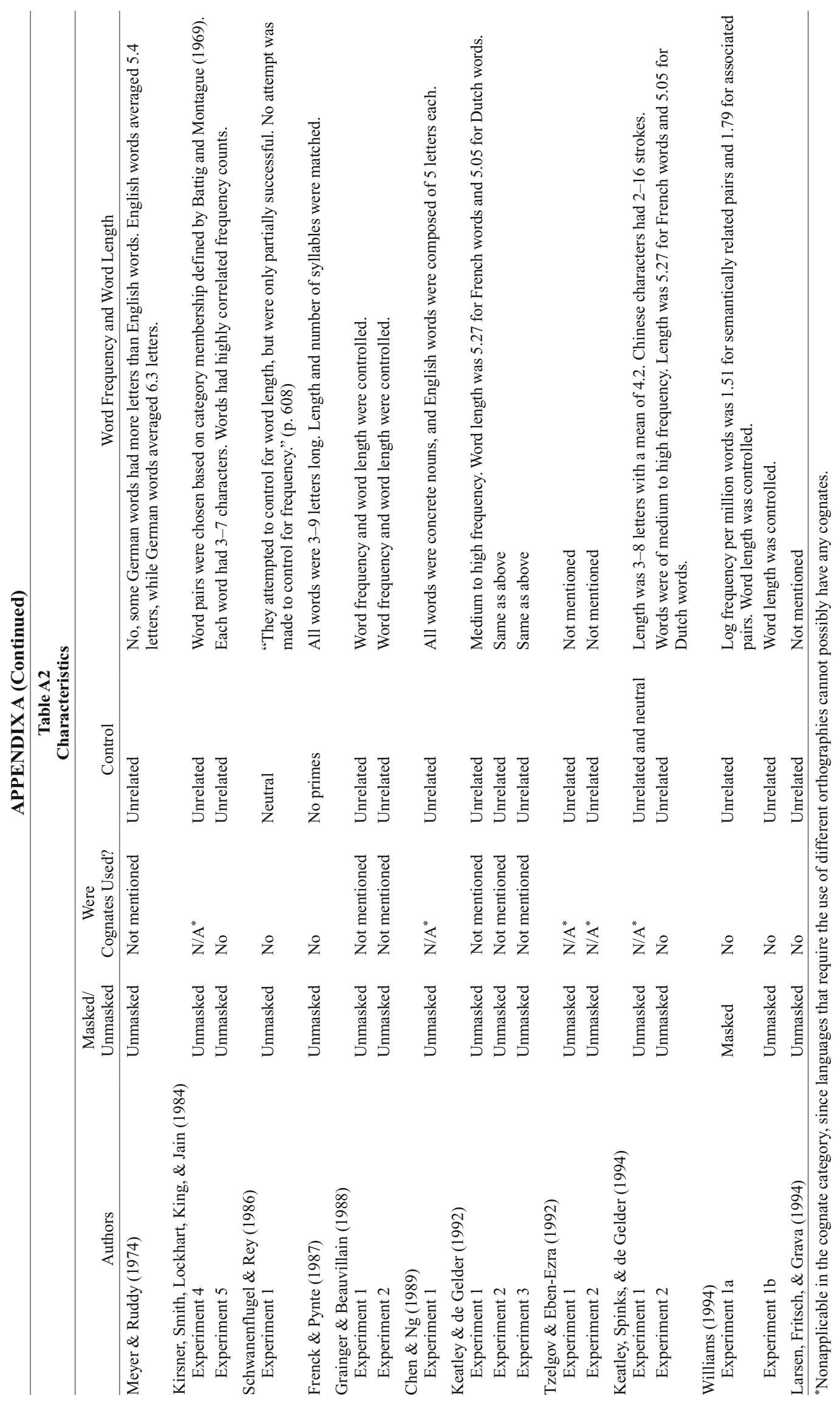




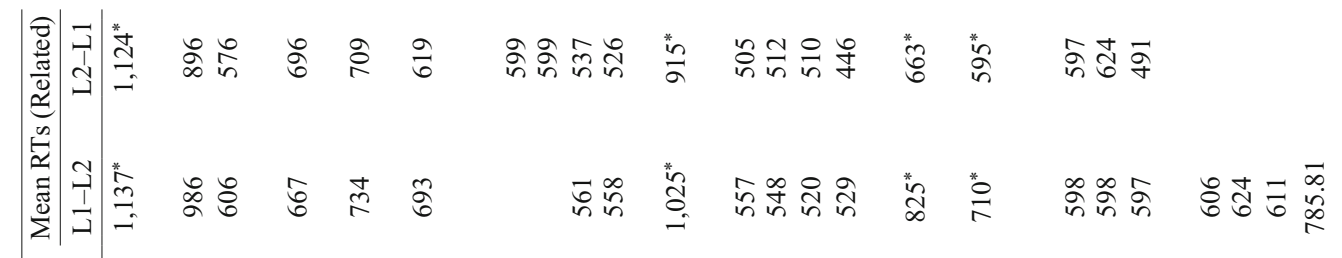

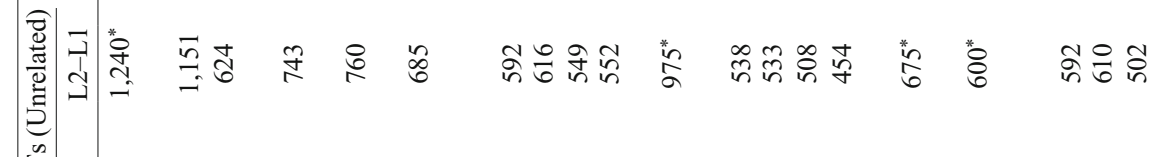

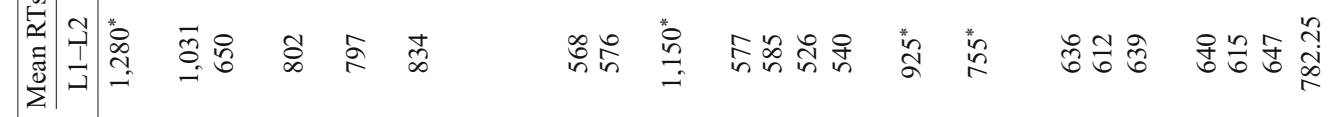
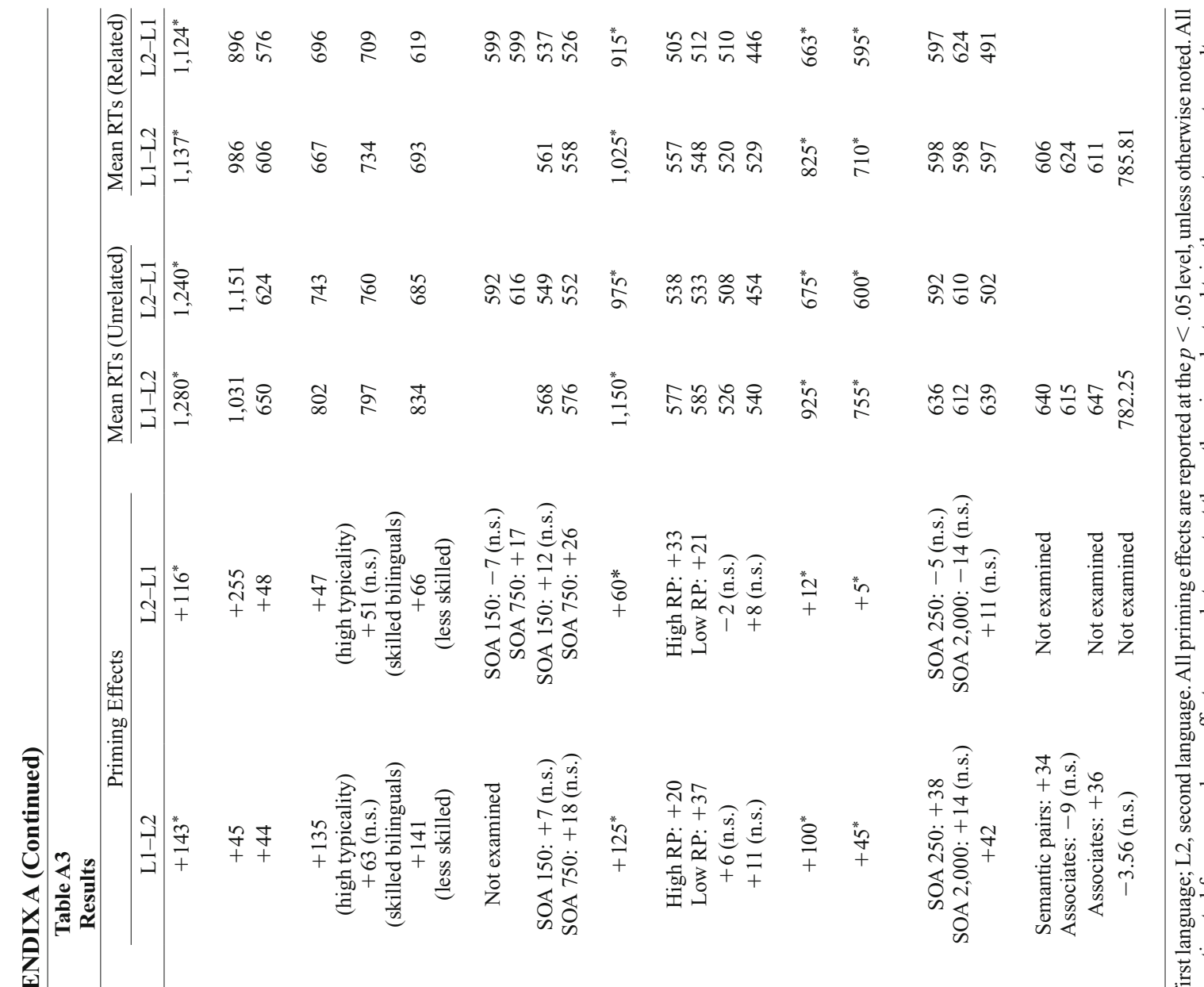

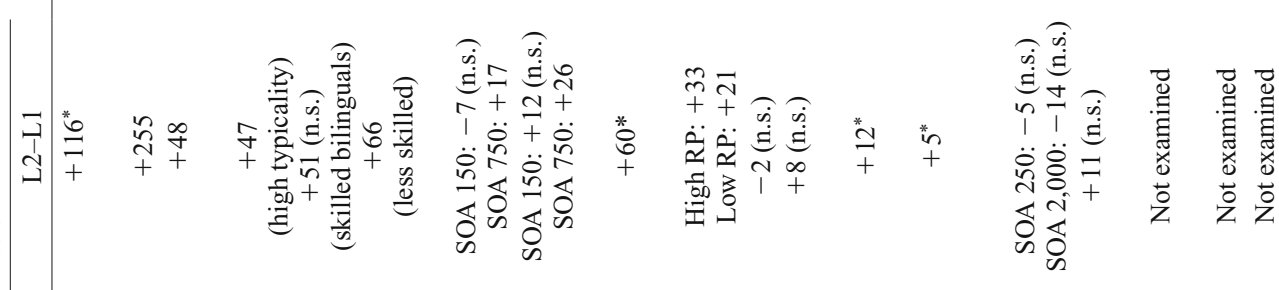

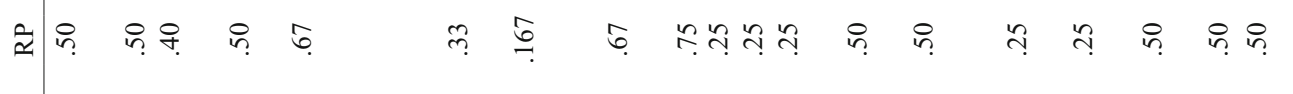

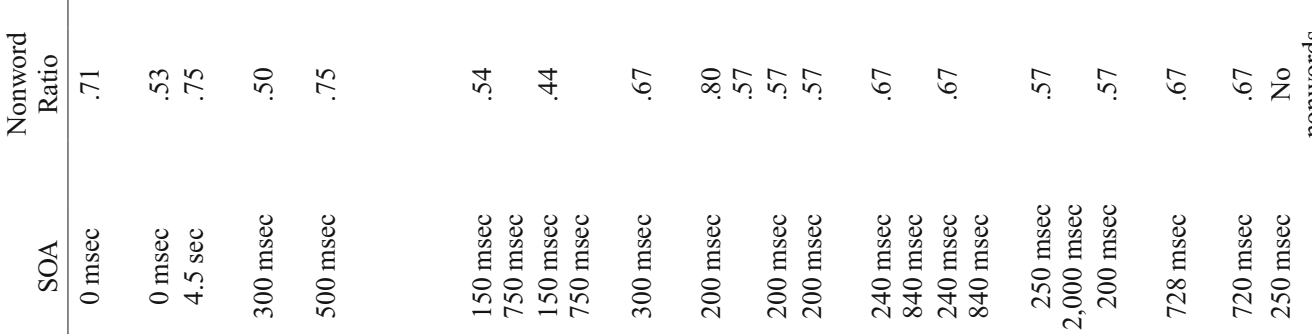
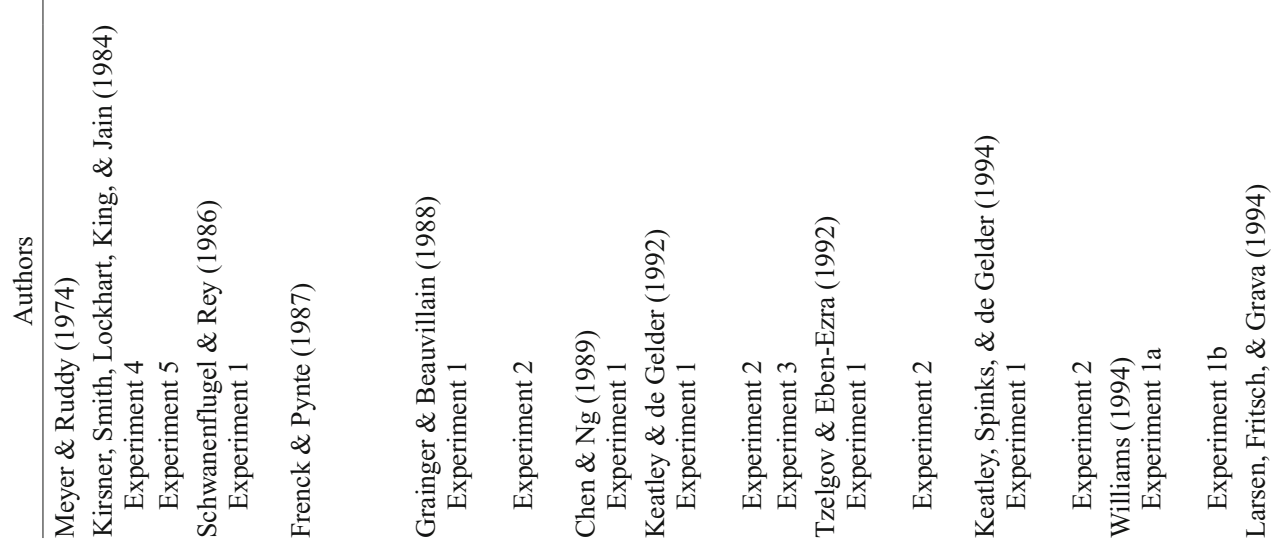


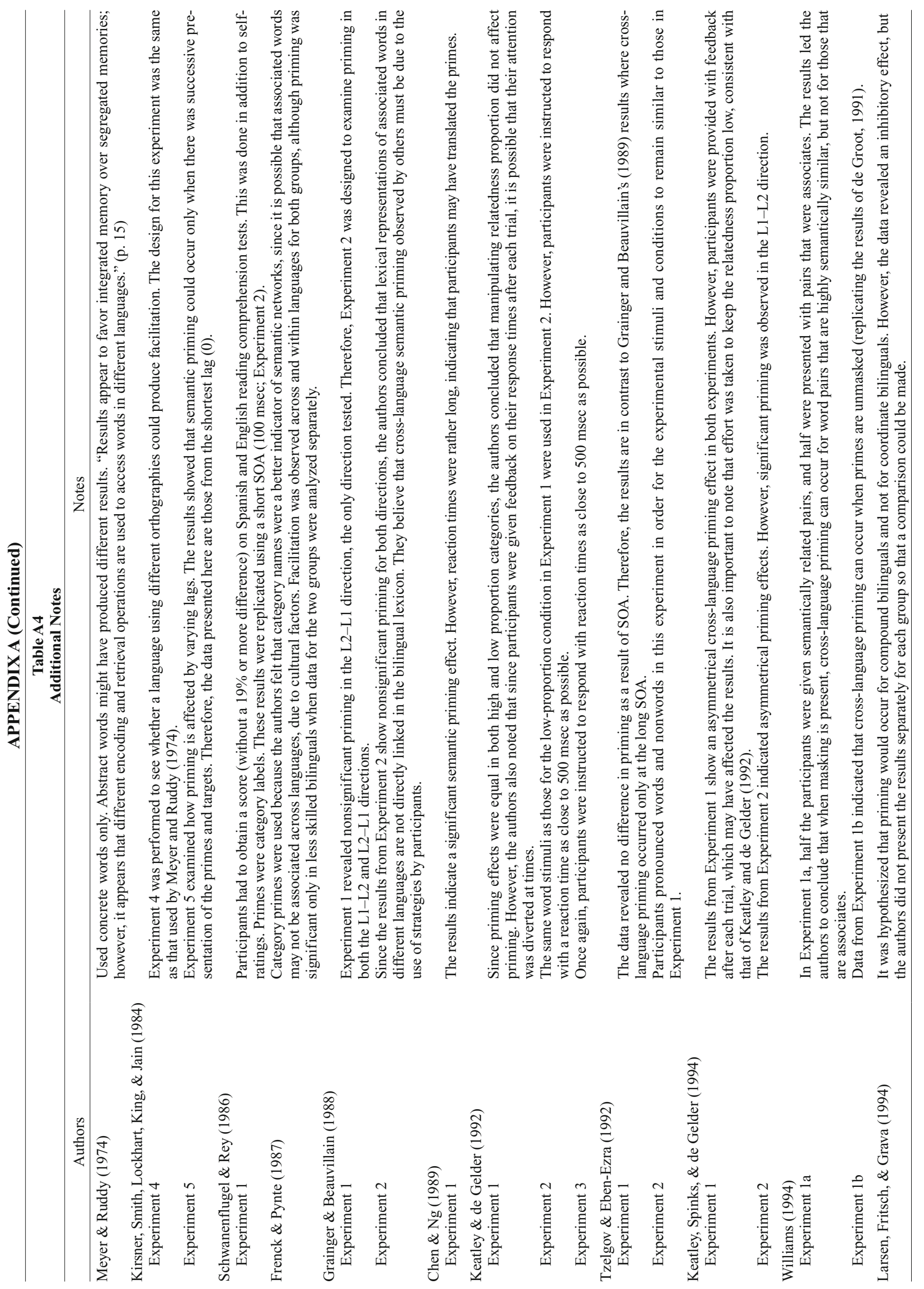




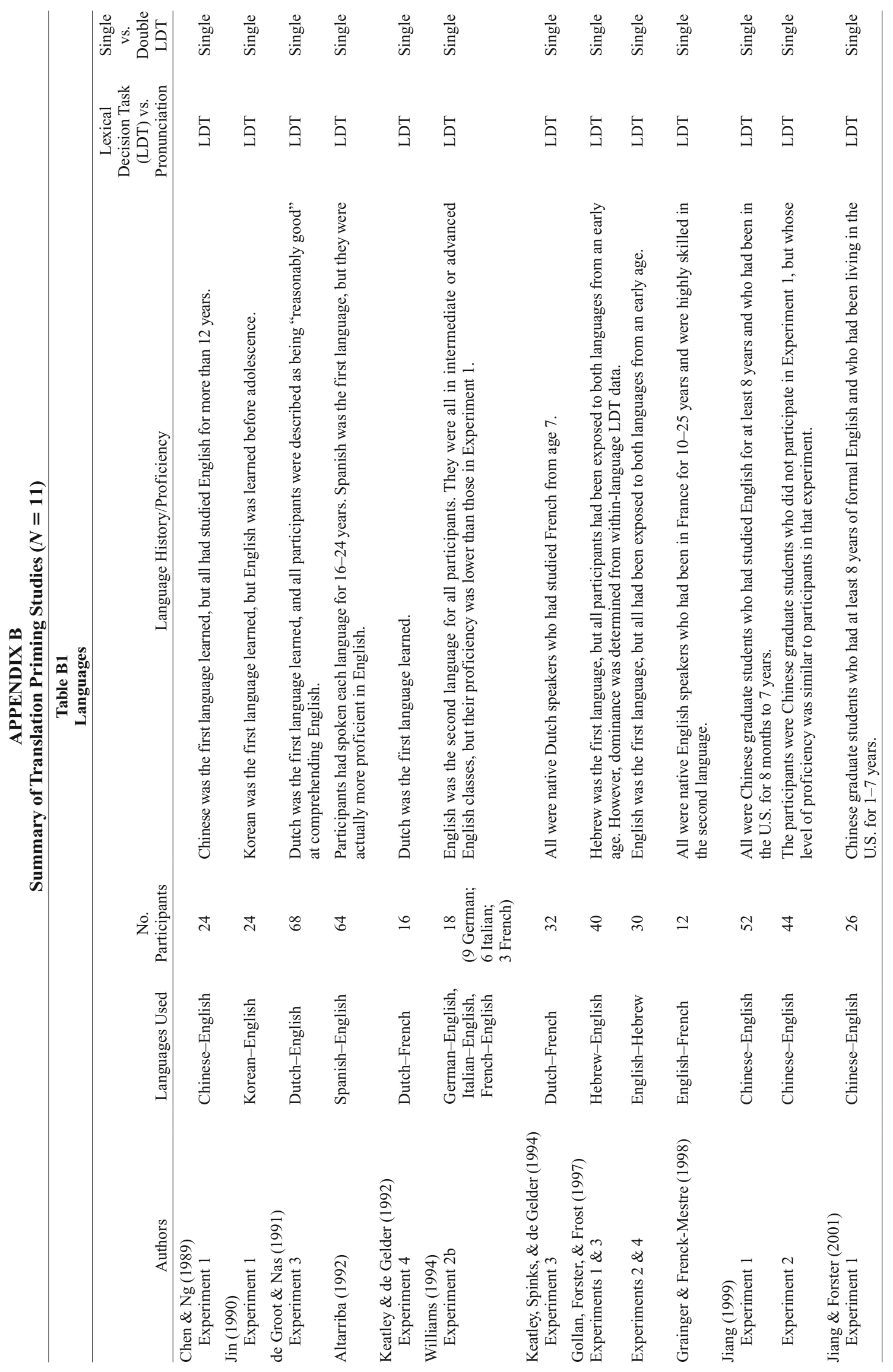




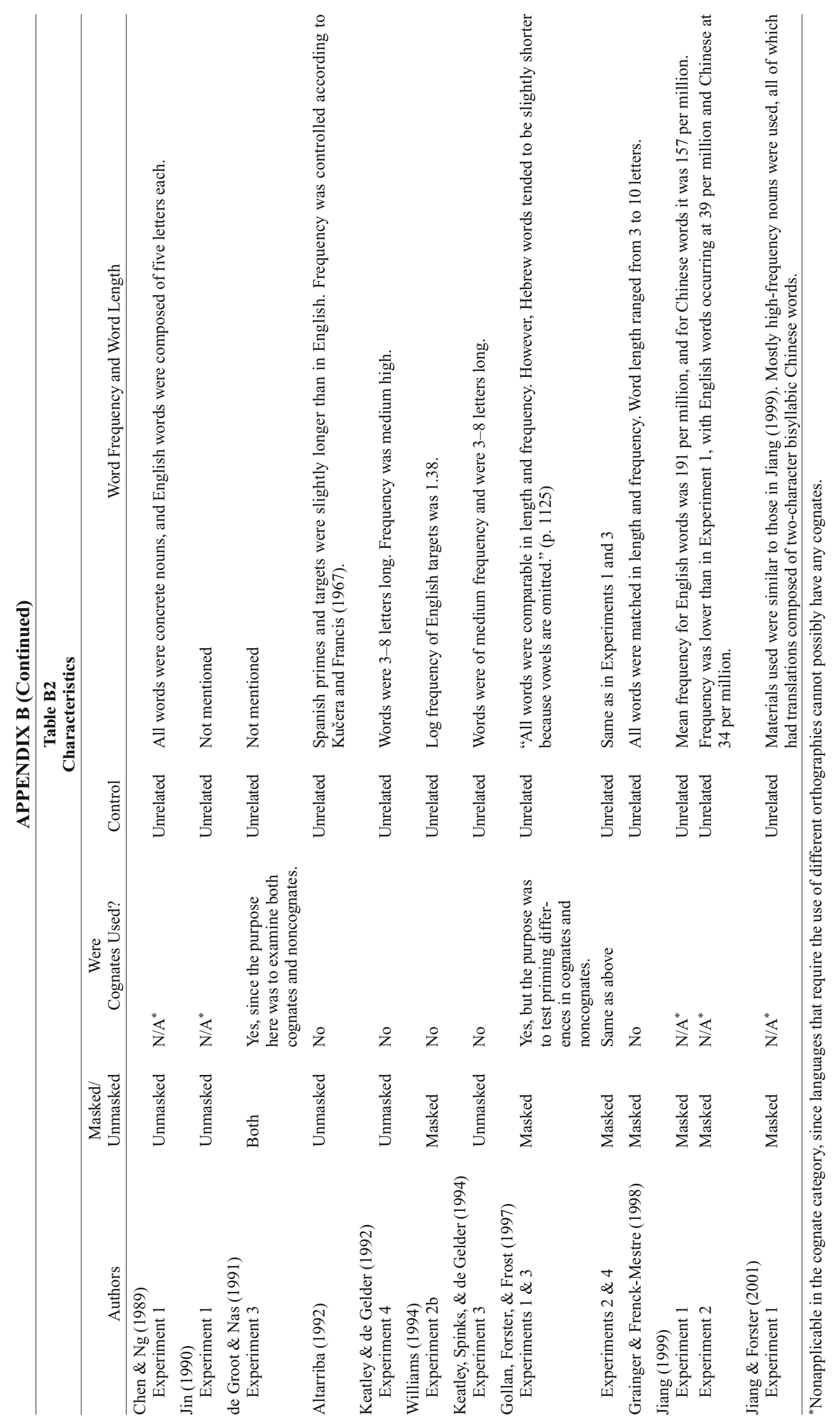




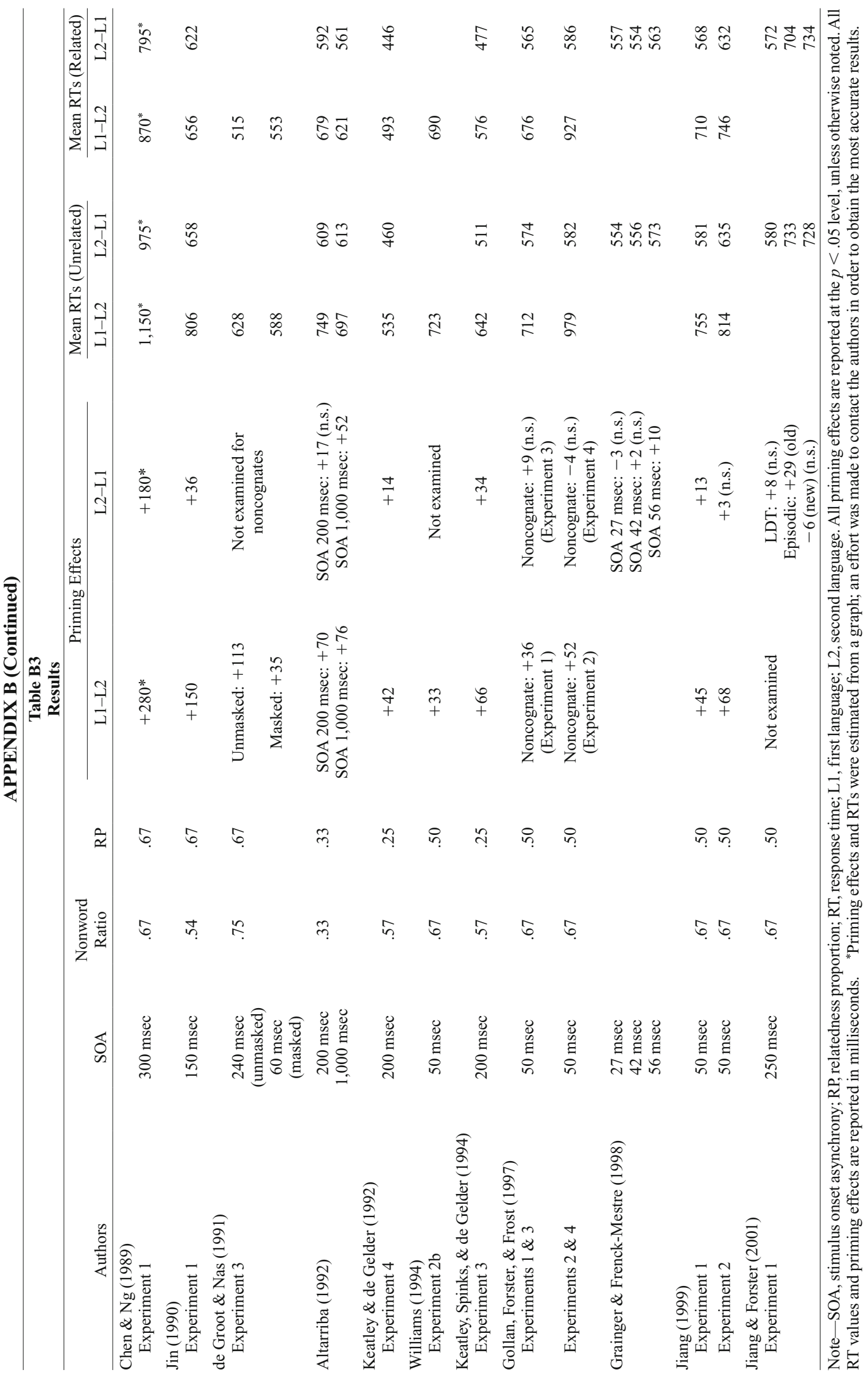




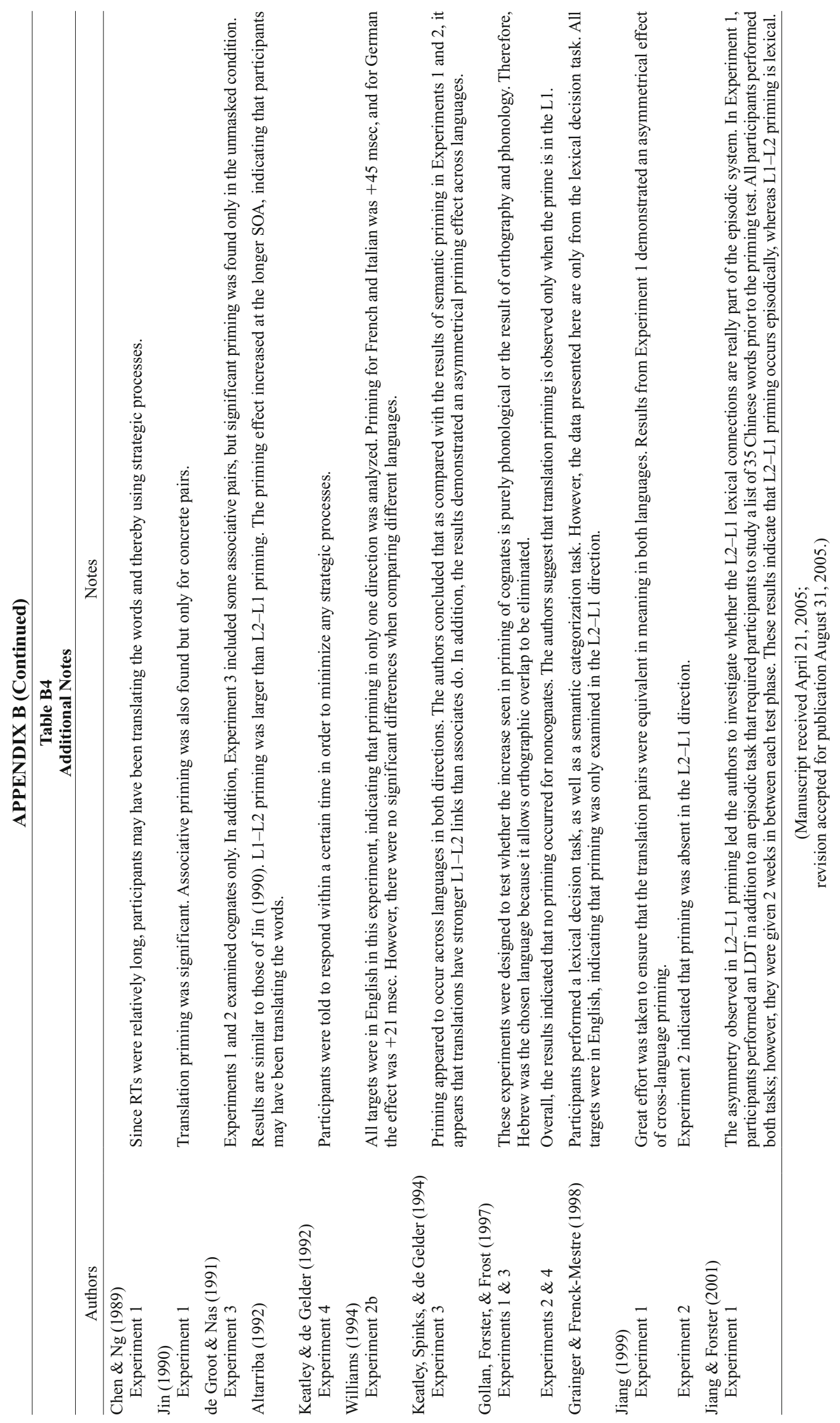

